\title{
Development of Antibacterial Nanocomposite: Whey Protein-Gelatin-Nanoclay Films with Orange Peel Extract and Tripolyphosphate as Potential Food Packaging
}

\author{
Behrokh Shams $\mathbb{D}^{1},{ }^{1}$ Nadereh Golshan Ebrahimi $\mathbb{D}^{1},{ }^{1}$ and Faramarz Khodaiyan ${ }^{2}$ \\ ${ }^{1}$ Polymer Engineering Department, Chemical Engineering Faculty, Tarbiat Modares University, P. O. Box 14115-114, Tehran, Iran \\ ${ }^{2}$ Department of Food Science, Engineering \& Technology, Faculty of Agricultural Engineering and Technology, University of Tehran, \\ P.O. Box 4111, Karaj 31587-77871, Iran
}

Correspondence should be addressed to Nadereh Golshan Ebrahimi; ebrahimn@modares.ac.ir

Received 10 July 2018; Revised 15 May 2019; Accepted 26 May 2019; Published 18 June 2019

Academic Editor: Alexandra Muñoz-Bonilla

Copyright (C) 2019 Behrokh Shams et al. This is an open access article distributed under the Creative Commons Attribution License, which permits unrestricted use, distribution, and reproduction in any medium, provided the original work is properly cited.

\begin{abstract}
Antibacterial and biodegradable whey protein isolate (WPI-) gelatin nanocomposites were prepared using natural orange peel extract (OPE) in percentage of 7, 14, and 21\% (v/v solution) and Cloisite 30B (5\% w/w dry whey protein) made by a casting method. Mechanical, physical, and antibacterial properties of prepared films were measured as a function of OPE concentration. Higher concentrations of OPE led to higher antibacterial activity, tensile strength, and water solubility, but lower moisture content and transparency. The films microstructures were studied by field emission scanning electron microscopy (FESEM) and ATR-FTIR. Overall, the film containing $21 \%(\mathrm{v} / \mathrm{v})$ OPE resulted in the best antibacterial, mechanical, and physical performance. Addition of tripolyphosphate (TPP) as a crosslinker to this sample led to the significant increase in transparency. Cloisite 30B, OPE, and TPP can therefore be used to improve the properties of WPI films as a promising natural food packaging.
\end{abstract}

\section{Introduction}

In 2013, 13360 illnesses, 1062 hospitalizations, and 16 deaths in USA have been reported by Centers for Disease Control and Prevention, National Public Health Institute of the United States of America, caused by food illnesses [1]. One of the reasons for food illnesses is bacterial pollution. As a result, a lot of researches were being focused on using antibacterial food packaging to eliminate or inhibit the activity of bacteria. On the other hand, disposal of waste plastic packaging material has also polluted the environment, majorly due to the fact that most of the plastic packaging materials are not biodegradable. Hence antibacterial and edible food packaging can be beneficial in terms of environment and shelf life.

Proteins are used in edible packaging because of their good film-forming abilities, making them ideal base materials for these applications [2]. Whey protein is a byproduct of dairy industries with excellent oxygen, aroma, and oil barrier properties; however, using pure whey protein to produce food packaging is not affordable [3]. Gelatin is another protein which has been used in food packaging and is derived from wastes during animal slaughtering. Gelatin films are transparent and typically exhibit good gas barrier properties, with their gel strength expressed by bloom value and high bloom gelatin makes strong gels. Generally, protein-based films exhibit lower mechanical properties compared with synthetic films but gelatin showed higher tensile strength and elongation compared to some other protein-based films [4]. Different approaches have been used to improve whey protein films such as UV-Radiation but it just boosted tensile strength and yellow color of films. So it seems that blending whey protein and gelatin could omit the defects of each component. For example, there have been reports that blending WPI with chitosan [5] or konjac glucomannan as a polysaccharide [6] resulted in increased flexibility compared with pure WPI film. 
Also, tensile strength of WPI-gelatin blend film was much higher than pure WPI film because gelatin has stronger gel than WPI [7].

Montmorillonite (MMT), in addition to being economic and available, is one of the most important nanoclay particles used in nanocomposites. Due to nanoclay's large aspect ratio, nanocomposites prepared by nanoclay exhibit higher biodegradability and have ideal barrier properties and strength compared with pure polymers and microcomposites $[8,9]$. Azevedo et al. showed that Cloisite $\mathrm{Na}^{+}$, unmodified MMT, in combination with citric acid, lowered the moisture content and water vapor permeability of WPI films [10]. Wakai et al. concluded that the presence of nanoclay in nanocomposite based on whey protein leads to a decrease in water solubility and elongation at break as well as an increase in tensile strength [11]. In 2010, Sothornvit and his coworkers produced whey protein composites by addition of different percentages of organically modified MMT, Cloisite 30B. They concluded that, by increasing nanoclay concentration, the barrier properties and tensile strength also increased [12]. In 2009, Sothornvit et al., in another research, prepared whey protein composite films by different types of nanoclay, Cloisite $\mathrm{Na}^{+}, 20 \mathrm{~A}$, and 30B, showing that the highest tensile strength was related to WPI/Cloisite 30B composite exhibiting antibacterial activity against Grampositive bacteria, Listeria monocytogenes [13].

Incorporation of antibacterial and antioxidant agents into biodegradable films is taken into consideration. For instance, Aloe vera, pomegranate peel, and curry leaf extracts, oregano, garlic, rosemary, Zataria multiflora, hemp, and sage oil have all been used to develop antibacterial properties of whey protein and gelatin based films, respectively [14, 15]. Seydim et al. produced WPI-based films by oregano, garlic, and rosemary oils, studying their activity against Escherichia coli and Staphylococcus aureus. It was observed that incorporating osemary into WPI films did not exhibit any antibacterial activity whereas oregano and garlic oils created antibacterial activity in films increasing by their concentration [16]. In similar research, sodium lactate and 3-polylysine were added to WPI films and the antibacterial activity of the films was tested on fresh beef cut portions. Inhibition of growth of the total flora, pseudomonads, and also lactic acid bacteria was observed in the films containing sodium lactate and 3polylysine, respectively [4].

In the recent years, some researchers have used nanoparticles as an active agent in bioplastics. For instance, Shankar and his coworkers added copper oxide nanoparticles (CuONPs) to various types of carbohydrate biopolymers and samples exhibited strong antibacterial activity against Escherichia coli and Listeria monocytogenes [17]. Besides, researchers developed edible nanocomposites based on chitosan/starch corn and cellulose nanofibrils (CNFs) as an antibacterial agent and consequently antimicrobial properties of the edible films with $80 \%$ and $100 \%$ w/w CNFs were increased by up to $2 \log \mathrm{CFU} / \mathrm{g}$ on day 8 in a beef model [18]. In another research, a combination of montmorillonitecopper oxide (MMT-CuO) was used to produce antibacterial films based on chitosan. As a result, films showed more than 99\% mortality against two Gram-negative bacteria (E. coli
(PTCC 1270) and P. aeruginosa (PTCC 1430)) and two Grampositive bacteria (S. aureus (PTCC1112) and B. cereus (PTCC1015)) [19]. Generally physical and chemical properties of polymer and nanoparticles may affect removing targeted bacterias [20].

Nanoparticles are also able to positively affect active agent's function due to preserving the integrity of incorporated bioactive agents as well as control of the release rate [21].

Although both synthetic and natural antibacterial agents are used in active packaging, plant extracts are preferred as synthetic, due to not having chemical compounds and solvents which can be potentially hazardous. The aims of this study were therefore to prepare a new antibacterial and biodegradable nanocomposite film based on WPI-gelatin, with potential application as a food packaging, and to determine the physical, mechanical, and barrier as well as antibacterial properties of resultant films as a function of nanoclay and orange peel extract concentration.

As unique aspects of this study it should be mentioned that WPI is side product of dairy industries and OPE is produced by orange peel as a waste material. Somehow, WPI-gelatin films in this research could be used as an entirely natural and economically affordable, potential food packaging.

\section{Materials and Methods}

2.1. Materials. Whey protein isolate (WPI, $86 \mathrm{wt} \%$ protein) was purchased from Self Omninutrition (Sweden). Gelatin in food grade (the bloom degree: 240-260) was kindly supplied by Faravari Darooyi Gelatin Halal (Ghazvin, Iran). Glycerol and acetone were purchased from Dr. Mojallali (Tehran, Iran). Orange fruits were obtained from Tehran market (Iran) to prepare orange peel extract. Organically modified MMT (Cloisite 30B) with a density of $1980 \mathrm{Kg} / \mathrm{m}^{3}$ was purchased from Southern Clay Products Inc. (Gonzalez, TX). Tripolyphosphate (TPP) and vermicompost were purchased from Scharlau (Barcelona, Spain) and Gilda Kood (Tehran, Iran), respectively.

2.2. Preparation of Orange Peel Extract. Peels of orange fruits were dried in ambient air. Peels were ground by house mill and $0.4 \mathrm{~g}$ of orange peel powder dispersed in $20 \mathrm{ml}$ of $70 \%$ $(\mathrm{v} / \mathrm{v})$ acetone solution by means of ultrasonic homogenizer (UP400S, Hielscher, Germany, 400 watts, $24 \mathrm{kHz}, 25^{\circ} \mathrm{C}$ ) for 20 $\mathrm{min}$ at room temperature. The solution was then centrifuged at $\left(4^{\circ} \mathrm{C}, 3000 \times \mathrm{g}\right)$. The upper phase of obtained two-phase solution was separated as orange peel extract [22].

2.3. Preparation of Bioactive Films. A 5\% (w/v) WPI-gelatin solution was prepared by dispersing $1 \mathrm{~g}$ of WPI in $20 \mathrm{ml}$ of distilled water and heated in a water bath at $90^{\circ} \mathrm{C}$ for $30 \mathrm{~min}$ and rapidly cooled in the refrigerator to prevent further denaturation [23, 24]. Demonstrating the highest tensile strength as well as second highest tensile strain among the counterparts, the sample containing $2 \%(\mathrm{w} / \mathrm{v})$ of gelatin was chosen as the optimum specimen in the first phase of sample preparation. Somehow, this amount of gelatin was added to the aforementioned solution while being stirred for 
a further $15 \mathrm{~min}$ [25]. Following 15 min stirring, glycerol as plasticizer ( $40 \%$ of total solid weight) was incorporated into the film-forming solution to obtain more flexible films [26]. The film solution was subsequently transferred into a vacuum oven at room temperature for $30 \mathrm{~min}$ to remove most of the air bubbles trapped during stirring. In contrast, 5\% (w/w dry WPI) of Cloisite 30B was dispersed with distilled water (10 $\mathrm{ml}$ ) and stirred using a magnetic stirrer overnight to reach complete hydration/swelling [13]. This solution was mixed with $10 \mathrm{ml}$ of $5 \%(\mathrm{w} / \mathrm{v})$ WPI-gelatin solution and sonicated for $30 \mathrm{~min}$, to obtain nanocomposite film. OPE in different concentrations was added to the solution of nanocomposite films containing 5\% nanoclay (w/w dry WPI) and stirred to obtain homogeneous solutions [14]. In the last step, about 20 $\mathrm{ml}$ of each sample was cast onto the flat level plastic plates and was held at room temperature for $18 \mathrm{~h}$ to set. Then, they were peeled off the casting surface and stored in plastic bags inside desiccators at $25 \pm 1^{\circ} \mathrm{C}$ for further testing. All treatments were made in triplicate. Table 1 shows the composition and symbol of all prepared film samples. According to Table 1, WGN-21TPP was produced in a way similar to the other bioactive films but before casting step, TPP $(0.75 \mathrm{w} / \mathrm{v} \%)$ was added to the film solution and stirred at $900 \mathrm{rpm}$ until it was completely dissolved in solution.

\subsection{Structural Characteristics}

2.4.1. Field Emission Scanning Electron Microscopy (FESEM). All the specimens were examined by FESEM (Mira3, TE Scan, Czech Republic). The samples were fractured in liquid nitrogen and coated with gold prior to FESEM imaging at an accelerating voltage of $15 \mathrm{kV}$ and different magnitudes. The resolution was 2 to $200 \mu \mathrm{m}$ (magnification of micrographs was $100 \mathrm{x}$ for surface and $10000 \mathrm{x}$ for a cross section of the films).

2.4.2. FTIR-ATR Analysis. The spectra of the surface of the films were determined using Fourier Transform Infrared Spectrometry (FTIR) with a spectrometer (Frontier, Perkin Elmer, Boston MA, USA), under attenuated total reflectance [27] mode. The spectra were recorded in absorbance mode from 1800 to $4000 \mathrm{~cm}^{-1}$, using 16 scans at $4 \mathrm{~cm}^{-1}$ resolution.

\subsection{Physical Properties}

2.5.1. Film Thickness. The thickness of the films was measured using a hand-held micrometer (Alton M820-25, China) with an accuracy of $0.01 \mathrm{~mm}$. The thickness of 10 randomly selected points was measured for each testing specimen and the mean value was reported.

2.5.2. Water Vapor Permeability. The films' water vapor permeability (WVP) was gravimetrically measured according to the standard method and corrected for the stagnant air gap inside test cups [28]. At first, the measurement cells (mouth area $1.33 \times 10^{-4} \mathrm{~m}^{2}$ ) were filled with water to create $100 \%$ relative humidity $(\mathrm{RH})$, so that the air gap between the water surface and the mouth of the cell would be $1.5 \mathrm{~cm}$. The mouth of the cells was covered with the films and sealed with doublesided adhesive tape. Cells were kept in the oven (Model GTH072TR, Giant Force Instrument, Taiwan) of 50\% RH using prepared by sodium chloride at $25^{\circ} \mathrm{C}$. The cells were weighted at certain intervals and linear regression analysis of weight loss versus time was performed. Water vapor transmission rate (WVTR) was calculated from the constant rate of weight loss divided by film area and consequently, water vapor permeability (WVP) was calculated by the following equation [26]:

$$
\begin{aligned}
& \text { WVP } \\
& =\frac{\text { Thickness }(\mathrm{m}) \times \text { WVTR }(\mathrm{g} / \mathrm{m} 2 . \mathrm{s}) .}{\text { Pressure difference between two sides of the film }(\mathrm{Pa})}
\end{aligned}
$$

the difference in vapor pressure between the two faces of the film is calculated from the equation: $\Delta P=S\left(R_{1}-R_{2}\right)$; $S$ is the saturated vapor pressure at the test temperature $(2.1 \mathrm{kPa}), \mathrm{R}_{1}$ is the RH on the wet side of the cell (100\%), and $\mathrm{R}_{2}$ is the $\mathrm{RH}$ on the dry side of the cell (50\%).

2.5.3. Moisture Absorption. The film samples were cut in dimensions $(2 \mathrm{~cm} \times 2 \mathrm{~cm})$ and dried at $105^{\circ} \mathrm{C}$ for $1 \mathrm{~h}$. Then, they were weighted $\left(\mathrm{m}_{1}\right)$ and put into an oven equilibrated at $25^{\circ} \mathrm{C}$ and $50 \% \mathrm{RH}$ at $25^{\circ} \mathrm{C}$ with a saturated sodium chloride solution. Samples were weighted at certain intervals until a constant weight $\left(\mathrm{m}_{2}\right)$ was achieved. Three replicates were carried out for each sample. The moisture absorption was calculated by the following equation [26]:

$$
\text { Moisture absorption }=\frac{\mathrm{m} 2-\mathrm{m} 1}{\mathrm{~m} 1} \times 100
$$

2.5.4. Water Solubility. The film samples $(20 \mathrm{~mm} \times 20 \mathrm{~mm}$ $\times 0.1 \mathrm{~mm}$ ) were placed in an oven at $104^{\circ} \mathrm{C}$ for $24 \mathrm{~h}$ and then were weighed. The dried films were immersed in $50 \mathrm{ml}$ of distilled water and stirred for $24 \mathrm{~h}$. Thereafter, the remaining solutions were decanted on the surfaces of filter papers and placed in the oven at $104^{\circ} \mathrm{C}$ for $24 \mathrm{~h}$ and then weighed again. This was considered as " $\mathrm{W}_{\mathrm{f}}$ ". The water solubility percentage (S\%) was determined by using the following equation [14]:

$$
\mathrm{S}(\%)=\left[\frac{\left(\mathrm{W}_{\mathrm{i}}-\mathrm{W}_{\mathrm{f}}\right)}{\mathrm{W}_{\mathrm{i}}}\right] \times 100
$$

The reported results are the average of at least three measurements.

2.5.5. Moisture Content. Pieces of films with dimensions of 3 $\times 1 \mathrm{~cm}^{2}$ were cut, weighted, and dried in an oven at $110^{\circ} \mathrm{C}$ to reach the constant weight. The moisture content (MC) on the basis of wet weight was determined as follows [26]:

$$
\mathrm{MC}=\frac{\text { wet sample weight }- \text { dry sample weight }}{\text { wet sample weight }} \times 100
$$

2.5.6. Transparency. Film transparency was determined by measuring the transmittance of the films at $600 \mathrm{~nm}$ using a UV/vis spectrophotometer (Model 3220, Optizen, Korea) 
TABLE 1: Different concentrations of components for preparing films and their symbols.

\begin{tabular}{lccc}
\hline Film symbol & Nanoclay $(\% \mathrm{w} / \mathrm{w}$ WPI) & OPE (\%w/v) & TPP (\%w/v) \\
\hline WG $^{\text {a }}$ & 0 & 0 & 0 \\
WGN5 $^{\mathrm{b}}$ & 5 & 0 & 0 \\
WGN5-7 $^{\mathrm{c}}$ & 5 & 7 & 0 \\
WGN5-14 $^{\mathrm{d}}$ & 5 & 14 & 0 \\
WGN5-21 $^{\mathrm{e}}$ & 5 & 21 & 0 \\
WGN5-21-TPP $^{\mathrm{f}}$ & 5 & 21 & 0.75 \\
\hline
\end{tabular}

$a$ WG demonstrates the WPI-gelatin film sample containing $5 \%(\mathrm{w} / \mathrm{v})$ WPI and $2 \%(\mathrm{w} / \mathrm{v})$ of gelatin.

$b$ demonstrates WG films added by 5 (\%w/w WPI) of nanoclay

$c, d$ and $e$ demonstrate WGN5 films added by 7,14 and $21(\% \mathrm{w} / \mathrm{v})$ of orange peel extract respectively.

$f$ demonstrates WGN5-21 films added by $0.75(\% \mathrm{w} / \mathrm{v})$ of Sodium triphosphate.

[26]. The transparency of the films was calculated by the following equation:

$$
\text { Transparency value }=-\frac{\log \mathrm{T}_{600}}{\mathrm{X}}
$$

where $\mathrm{T}_{600}$ is the transmittance at $600 \mathrm{~nm}$ and $\mathrm{x}$ is the film thickness (mm).

2.6. Mechanical Properties. The films were cut into $2 \times 10 \mathrm{~cm}^{2}$ pieces and maintained for moisture equilibrium in an oven at $25^{\circ} \mathrm{C}$ and $50 \% \mathrm{RH}$ for $24 \mathrm{~h}$. Tensile strength (TS) and elongation at break (EB) were evaluated by the Instron machine (Model 5566, USA) according to the ASTM standard method D882-02 [29]. Initial grip separation and crosshead speed were set at $50 \mathrm{~mm}$ and $60 \mathrm{~mm} / \mathrm{min}$, respectively [5], and the load cell was $5 \mathrm{~kg}$. Three replicates were run for each film specimen.

\subsection{Antibacterial Activity}

2.7.1. Viable Cell Count Assay. The quantitative antimicrobial activity of each WPI-gelatin nanocomposite film containing OPE, against the Gram-negative bacteria (E. coli, present in meat and cheese) and the Gram-positive bacteria (S. aureus), was evaluated using reference [30] originally designed for the evaluation of the antimicrobial activity of textile materials, adapted hereby to films. WPI-gelatin nanocomposite films (with and without incorporation of an antimicrobial compound) were thus cut into $50.0 \pm 1.0 \mathrm{~mm}$ diameter disks using a circular knife and were exposed to UV light for 10 min on each side. Each film disk was then placed in a 125 $\mathrm{ml}$ sterilized flask, to which $1 \mathrm{ml}$ of inoculum containing 105 (colony-forming unit (CFU)/ml) of each microorganism was added, so as to cover the entire disk. Flasks were incubated at $37^{\circ} \mathrm{C}$ for bacterial cultivation. Afterwards, $99 \mathrm{ml}$ of sterile peptone water $(1 \mathrm{~g} / \mathrm{l})$ was used as a neutralizing solution, aseptically added to each flask at $0,3,6,12$, and $24 \mathrm{~h}$ (sampling time). The flask content was then aseptically transferred to a $400 \mathrm{ml}$ homogenizing bag and blended in a Stomacher 400 reciprocal homogenizer (vortex mixer, Qiagen, Germany) for $1.0 \mathrm{~min}$ at $260 \mathrm{rpm}$. Appropriate sequential 10-fold dilutions of the homogenate were carried out in sterile peptone water (in triplicate) and plated $(0.02 \mathrm{~mL}$ per plate in duplicate) onto agar plates for the bacteria. The plates were then incubated as described above [31]. Enumeration of colonies was then performed, and inhibition of microorganism growth was expressed as a reduction of cell number or percentage of antibacterial potency (AP) using the following equation:

$$
\mathrm{AP}=\frac{\mathrm{A}-\mathrm{B}}{\mathrm{A}} \times 100
$$

where A is colonies of bacteria in control culture plate and $\mathrm{B}$ is colonies of bacteria in culture plate containing sample.

2.8. Statistical Analysis. Data analysis and mean comparison were performed with application of SPSS21 (SPSS Inc., Chicago, IL) and Duncan test in the level of $\mathrm{P}<0.05$, respectively. Excel software was applied for plotting data.

\section{Results and Discussion}

\subsection{Structural Characterization}

3.1.1. ATR-FTIR Analysis. In this study, ATR-FTIR was performed to identify the interaction of the polymer matrix with orange peel extract. Figure 1 represented the spectra of orange peel extract, WGN5, WGN-21, and WGN-21-TPP. A broad peak in the wavelength range $3200-3600 \mathrm{~cm}^{-1}$ belonged to the phenolic compounds that were the antibacterial agent of natural extracts and oils. As clearly seen, this peak is not observed in WGN5 but there were peaks in 3303 and $3435.57 \mathrm{~cm}^{-1}$ for WGN-21 and OPE, respectively, showing the presence of phenolic compounds on the surface of WGN21. No peak related to phenolic compounds was observed for WGN-21-TPP showing no extract on the surface of this sample. Presumably, it is because TPP makes a stronger network by creating crosslinks to the polymer matrix. So it is difficult for the OPE to penetrate from network to the surface of the film.

3.1.2. FESEM. Figure 2 shows the microstructure of WPIgelatin nanocomposite films using FESEM determinations. WGN5 displayed a compact, yet rough and low porosity structure that justified good dispersion of nanoparticles in the polymer matrix. (Figures 2(a) and 2(b)). Some white stains are observed on the surface of WGN-21 (Figure 2(c)). 


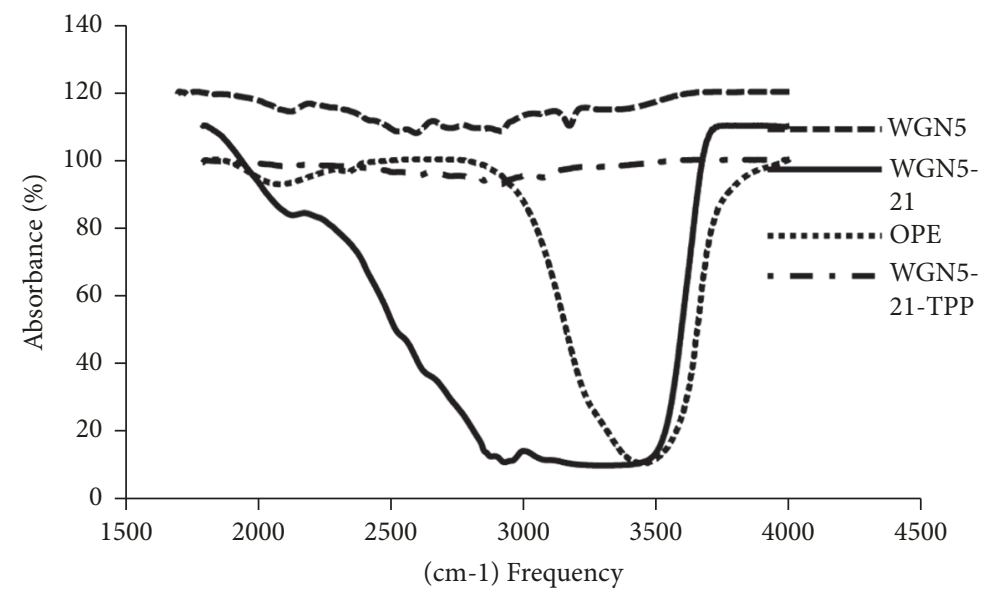

FIGURE 1: ATR-FTIR spectra of WGN5, WGN5-21, OPE extract and WGN5-4.2-TPP film samples.

Since whey protein and gelatin are hydrophilic and OPE is hydrophobic, OPE was expected to migrate to the surface of the film. So these white stains could be related to OPE. WGN21-TPP showed no white stains on the surface (Figure 2(e)). This might be because of establishing a more continuous structure by TPP since ionic crosslinker that trapped OPE in the polymer network did not allow it to migrate to the film surface. Results of ATR-FTIR confirmed this analysis. A similar analysis is presented for the migration of beeswax to the surface of WPI film [3]. In Figure 2(d), more roughness and porosity were observed compared with Figure 2(b). It could, therefore, be concluded that OPE interacted with some hydrophobic portions of the polymer matrix initially before migrating to the film surface and destroying these interactions retained some roughness in the cross-section of the film. Figure 2(f) showed more smooth and uniform structure for WGN-21-TPP in comparison with WGN-21 (Figure 2(d)). This might be because of the increase in miscibility of the polymer matrix and OPE due to the presence of the crosslinking agent.

\subsection{Physical Characterization}

3.2.1. Thickness. When considering the thickness rates of WPI-gelatin nanocomposite films, they were significantly different and in the range $0.07-0.1 \mathrm{~mm}$. Film thickness was increased by good dispersion of nanoclay in the polymer matrix.

3.2.2. Water Solubility. The water solubility percentages (weight loss) of the WPI/gelatin films are summarized in Table 2. Incorporation of OPE caused a significant increase in the solubility of films up to $35.9 \%$ in comparison with WGN5 $(p<0.05)$. This was the case, as natural extracts are inherently hydrophobic [32] and OPE is able to interact with some hydrophobic amino acids of gelatin and WPI and therefore may hinder polymer chain to chain interactions. Thus it is easier for polymer chains to be hydrated and soluble in water. Similar results and analysis were reported
[14]. Comparison of solubility of WGN-21-TPP and WGN21 showed that addition of TPP leads to decreasing water solubility. TPP probably have succeeded in stabilizing the structure of the polymer network due to the strong ionic crosslinks, making it difficult for network hydration, resulting in the reduction of water solubility.

3.2.3. Moisture Content. Table 2 displays the moisture percent available in WPI-gelatin nanocomposite films. Following the OPE addition, the moisture levels of the films declined significantly compared with the WGN5 sample $(\mathrm{p}<0.05)$. This could be explained by the hydrophobicity of OPE that does not allow the water molecules to occupy the empty spaces of the film network. Similarly, [15] reported that the moisture content was decreased by the incorporation sage and hemp oil into gelatin films. That was attributed to the hydrophilichydrophobic ratio of the constituents of the oils which give different abilities in water attraction and retention into the film network. Furthermore, the presence of TPP in WGN21-TPP decreased the moisture content in comparison with WGN-21. This was predictable, as the crosslinking developed by TPP in the film network does not allow water molecules to enter the structure of the polymer matrix.

3.2.4. Transparency. Transparency values (TV) of film samples comparing with literature results are gathered in Table 2. Bioactive film samples had lower TV than WGN5 film. Therefore it can be concluded that OPE made WPI-gelatin nanocomposite films opaque. This might be caused by the yellow color of OPE. Presence of TPP significantly increased the transparency of WGN-21-TPP compared with WGN-21. This was probably due to the enhancement in miscibility between polymer matrix and OPE caused by TPP. FESEM determination (Figure 2(e)) could be the reason for this claim. All samples of this study were more transparent than polyethylene and oriented polypropylene (OPP) synthetic films with T-values of 1.51 and 1.67 , respectively. In addition, all samples except WGN-21 were also more transparent than LDPE with T value of 3.05 [10]. It thereby promises a suitable 


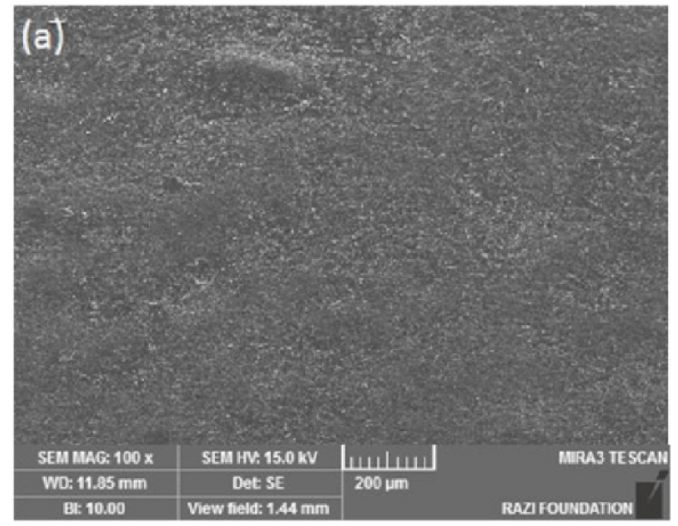

(a)

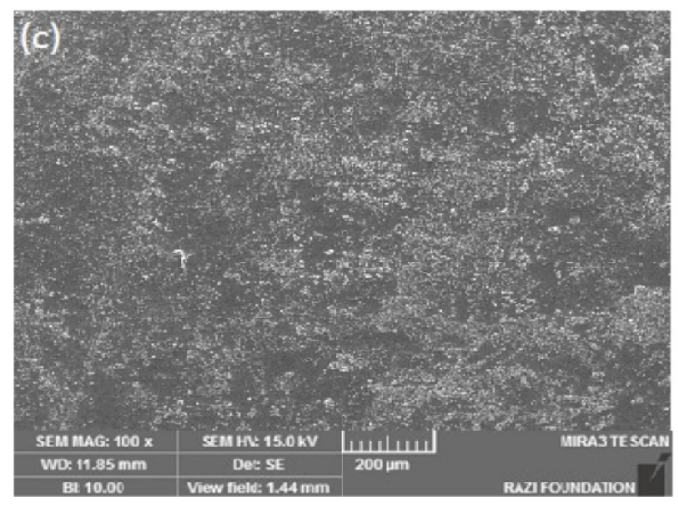

(c)

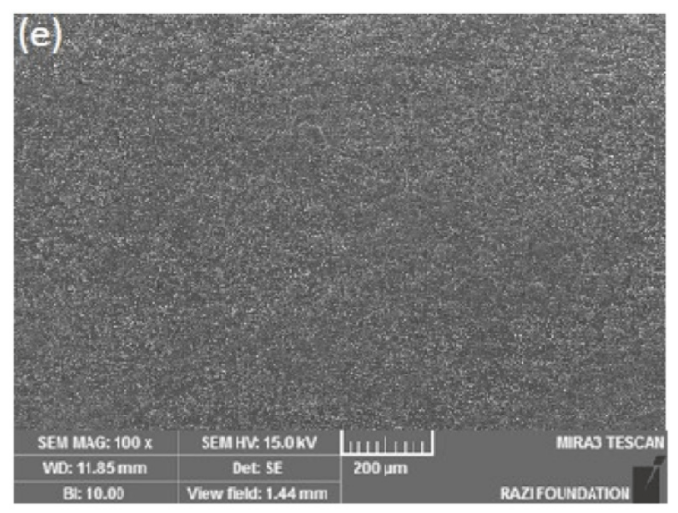

(e)

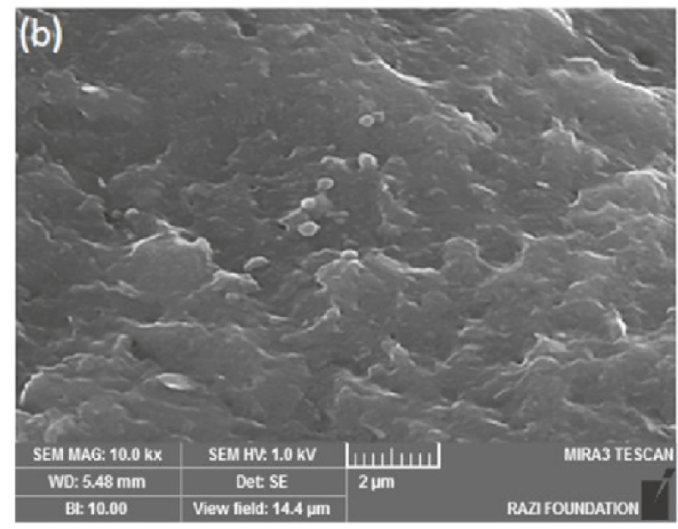

(b)

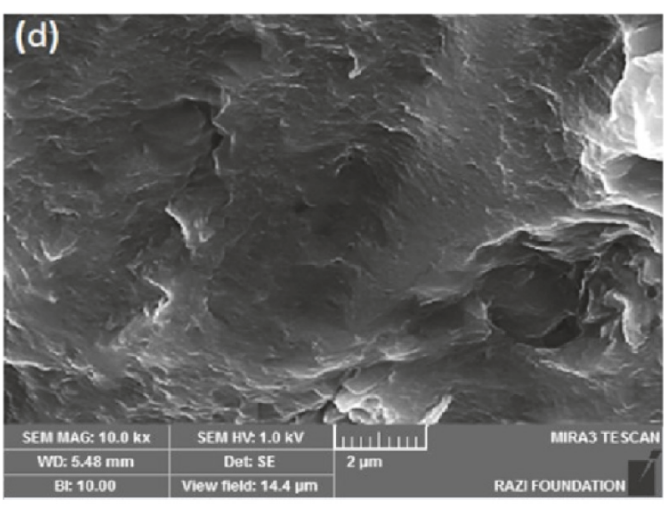

(d)

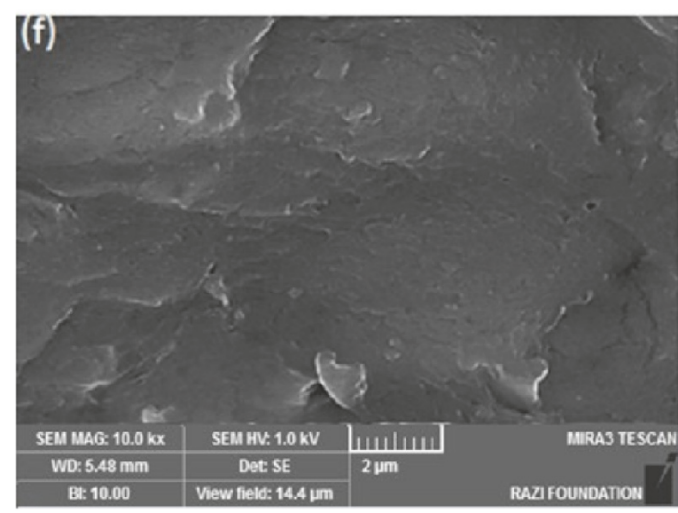

(f)

FIGURE 2: FESEM micrographs of WPI-gelatin based films: (a), (c) and (e) the surface; (b), (d) and (f) the cross section of WGN5, WGN5-21 and WGN5-21-TPP film samples.

TABLE 2: Effect of orange peel extract on physical and mechanical properties of WPI-gelatin-MMT-OPE films.

\begin{tabular}{lccccc}
\hline Films & Moisture content (\%) & Water solubility (\%) & Transparency & Tensile strength (MPa) & Elongation at break (\%) \\
\hline WG & $34.35 \pm 0.09^{\mathrm{a}}$ & $74.34 \pm 1.43^{\mathrm{a}}$ & $11.83^{\mathrm{a}}$ & $5.62 \pm 0.01^{\mathrm{a}}$ & $38 \pm 0.01^{\mathrm{a}}$ \\
WG N5 & $21.41 \pm 0.11^{\mathrm{b}}$ & $41.02 \pm 0.73^{\mathrm{b}}$ & $11.36^{\mathrm{a}}$ & $9.24 \pm 0.34^{\mathrm{b}}$ & $27 \pm 1.50^{\mathrm{b}}$ \\
WGN5-7 & $20.18 \pm 0.06^{\mathrm{c}}$ & $64.15 \pm 0.45^{\mathrm{c}}$ & $6.34^{\mathrm{b}}$ & $3.5 \pm 0.15^{\mathrm{c}}$ & $11 \pm 1.00^{\mathrm{c}}$ \\
WGN5-14 & $16.51 \pm 0.19^{\mathrm{d}}$ & $69.23 \pm 0.75^{\mathrm{d}}$ & $4.03^{\mathrm{c}}$ & $3.52 \pm 0.10^{\mathrm{c}}$ & $10 \pm 0.00^{\mathrm{c}}$ \\
WGN5-21 & $14.67 \pm 0.31^{\mathrm{e}}$ & $76.92 \pm 1.86^{\mathrm{a}}$ & $1.89^{\mathrm{d}}$ & $5.94 \pm 0.02^{\mathrm{a}}$ & $18 \pm 1.00^{\mathrm{d}}$ \\
WGN5-21-TPP & $13.76 \pm 0.06^{\mathrm{d}}$ & $71.79 \pm 0.98^{\mathrm{e}}$ & $4.18^{\mathrm{c}}$ & $6.41 \pm 0.58^{\mathrm{d}}$ & $13.99 \pm 1.00^{\mathrm{d}}$ \\
\hline
\end{tabular}

Means within the column with the same letters are not significantly different $(\mathrm{p}<0.05)$.

Data are means \pm SD. 
TABLE 3: Antibacterial properties of WPI-gelatin-MMT-OPE films. Means within the column with the same letters are not significantly different $(\mathrm{p}<0.05)$.

\begin{tabular}{|c|c|c|c|}
\hline Film samples & Bacteria & $\begin{array}{l}\text { Viable colony numbers } \\
(\mathrm{CFU} / \mathrm{ml})\end{array}$ & $\begin{array}{c}\text { Antibacterial potency } \\
(\%)\end{array}$ \\
\hline WGN5 & $\begin{array}{c}\text { E. coli } \\
\text { S. aureus }\end{array}$ & $\begin{array}{l}3.55 \times 10^{6} \\
2.90 \times 10^{7}\end{array}$ & 0 \\
\hline WGN5-7 & $\begin{array}{c}\text { E. coli } \\
\text { S. aureus }\end{array}$ & $\begin{array}{c}1.35 \times 10^{6} \\
\text { Uncountable } \geq 10^{8}\end{array}$ & $61.97^{\mathrm{a}}$ \\
\hline WGN5-14 & $\begin{array}{c}\text { E. coli } \\
\text { S. aureus }\end{array}$ & $\begin{array}{c}1.35 \times 10^{6} \\
\text { Uncountable } \geq 10^{8}\end{array}$ & $67.60^{b}$ \\
\hline WGN5-21 & $\begin{array}{l}\text { E. coli } \\
\text { S. aureus }\end{array}$ & $\begin{array}{c}2.80 \times 10^{6} \\
\text { Uncountable } \geq 10^{8}\end{array}$ & $92.39^{c}$ \\
\hline WGN5-21-TPP & $\begin{array}{l}\text { E. coli } \\
\text { S. aureus }\end{array}$ & $\begin{array}{c}3.81 \times 10^{6} \\
\text { Uncountable } \geq 10^{8}\end{array}$ & $89.26^{c}$ \\
\hline
\end{tabular}

application for use as packages that require a transparent appearance.

3.3. Mechanical Characteristics. Mechanical parameters of all film samples are shown in Table 2. Bioactive film samples showed significantly lower TS and EB than those of the WGN5 sample. According to similar results obtained [2, 33, 34], extracts or essential oils (i.e., oregano or cloves oils) caused rearrangement in the polymer network (e.g., alginate and gelatin) and in some cases, these oils are replaced instead of protein molecules in the polymer matrix. Hence, molecular interactions dropped out and a more discontinuous structure was created in comparison with the control film samples, resulting in the reduction of both TS and EB of samples. Meanwhile, Lee et al. reported that, by incorporating marjoram oil into gelatin films, TS and EB were enhanced and reduced, respectively [2]. The authors attributed this effect to the type and amount of phenolic compounds present in different oils that caused different interaction between oils and polymer matrix, creating different mechanical behaviors in bioactive films. In this research, higher TS and EB were observed for higher concentrations of OPE, as essential oils are hydrophobe [32] probably due to the interactions between OPE and hydrophobic domains of the polymer matrix, as the extract molecules penetrate in the polymer network and occupy the holes so that more continuous structure is obtained. As the number of hydrophobic amino acids in the polymer is lower than hydrophilic ones [35], the polymer matrix can be considered more hydrophilic rather than hydrophobic. That might be the reason why weak interaction between polymer and hydrophobe extract is observed in OPE lower concentrations.

Presence of TPP in WGN-21-TPP film led to a reduction in $\mathrm{EB}$ and increase in tensile strength compared with the WGN-21 sample, though not significantly.

3.4. Antibacterial Activity. Antibacterial activity of WPIgelatin films containing orange peel extracts against one Gram-negative bacterium (E. coli) present in meat and cheese products and one Gram-positive bacterium (i.e., S. aureus) was shown in Table 3. As observed, film samples with OPE displayed resistance against E. coli and their resistance was increased for a higher concentration of extract, meaning that the antibacterial potency for WGN-21 was $92.39 \%$ showing its good ability to enhance the shelf-life in food packaging applications. The effective component of orange peel extract is limonene [36, 37]. Its mechanism for resisting against $\mathrm{E}$. coli is disrupting the cytoplasmic membrane of bacteria [38]. In contrast, no antibacterial resistance was observed against S. aureus. Staphylococcus aureus is a strong bacterium and the most commonly isolated pathogen in domestic refrigerators [39]. This might explain why it displays resistance to the orange peel extract. However, this was in stark contrast to other conducted researches like [32] which reported that natural extracts are more effective on Gram-positive bacteria. Other reported literature concluded that the citrus extract had no antibacterial effect on Gram-positive bacteria. In another literature, an equal effect on both types of bacteria was observed. These conflicting results approve the diversity in extracts composition [39].

\section{Conclusion}

Antibacterial bionanocomposites were developed based on WPI-gelatin using nanoclay Cloisite 30B, OPE, and TPP as an antibacterial and crosslinking agent, respectively. Incorporation of OPE in the film composition led to a great antibacterial resistance against Gram-negative E. coli, especially for higher contents of OPE, but not for Gram-positive S. aureus. Moreover, even though addition of OPE caused a reduction in transparency, it did, however, increase flexibility of films. It is likely that the presence of TPP improves the miscibility between polymer matrix and OPE resulting in more transparent, compact, and smooth structure. However, as a limitation it led to a nonsignificant decrease in antibacterial activity. In the future research works, the effect of the higher concentrations of OPE on the mechanical and antibacterial properties of the films while maintaining the transparency properties could be studied.

It, therefore, seems that biodegradable and antibacterial WPI-gelatin-OPE nanocomposites have a great potential in food packaging applications for almost long-time storage. 


\section{Data Availability}

The data used to support the findings of this study are available from the corresponding author upon request.

\section{Conflicts of Interest}

The authors declare that they have no conflicts of interest.

\section{Acknowledgments}

The kind assistance of Tarbiat Modares University and Iran Nanotechnology Initiative Council is greatly acknowledged.

\section{References}

[1] https:/www.cdc.gov/foodsafety/pdfs/foodborne-disease-outbreaksannual-report-2013-508c.pdf.

[2] J.-H. Lee, J. Lee, and K. B. Song, "Development of a chicken feet protein film containing essential oils," Food Hydrocolloids, vol. 46, pp. 208-215, 2015.

[3] M. Khanzadi, S. M. Jafari, H. Mirzaei, F. K. Chegini, Y. Maghsoudlou, and D. Dehnad, "Physical and mechanical properties in biodegradable films of whey protein concentrate-pullulan by application of beeswax," Carbohydrate Polymers, vol. 118, pp. 2429, 2015.

[4] L. Espina, T. K. Gelaw, S. de Lamo-Castellví, R. Pagán, and D. García-Gonzalo, "Mechanism of bacterial inactivation by (+)limonene and its potential use in food preservation combined processes," PLoS ONE, vol. 8, no. 2, Article ID e56769, 2013.

[5] M. Kurek, S. Galus, and F. Debeaufort, "Surface, mechanical and barrier properties of bio-based composite films based on chitosan and whey protein," Food Packaging and Shelf Life, vol. 1, no. 1, pp. 56-67, 2014.

[6] M. Leuangsukrerk, T. Phupoksakul, K. Tananuwong, C. Borompichaichartkul, and T. Janjarasskul, "Properties of konjac glucomannan-whey protein isolate blend films," LWT- Food Science and Technology, vol. 59, no. 1, pp. 94-100, 2014.

[7] N. M. Sarbon, F. Badii, and N. K. Howell, "The effect of chicken skin gelatin and whey protein interactions on rheological and thermal properties," Food Hydrocolloids, vol. 45, pp. 83-92, 2015.

[8] M. Hassannia-Kolaee, F. Khodaiyan, R. Pourahmad, and I. Shahabi-Ghahfarrokhi, "Development of ecofriendly bionanocomposite: Whey protein isolate/pullulan films with nanoSiO2," International Journal of Biological Macromolecules, vol. 86, pp. 139-144, 2016.

[9] M. Zolfi, F. Khodaiyan, M. Mousavi, and M. Hashemi, "Development and characterization of the kefiran-whey protein isolate-TiO2 nanocomposite films," International Journal of Biological Macromolecules, vol. 65, pp. 340-345, 2014.

[10] V. M. Azevedo, E. K. Silva, C. F. Gonçalves Pereira, J. M. G. da Costa, and S. V. Borges, "Whey protein isolate biodegradable films: Influence of the citric acid and montmorillonite clay nanoparticles on the physical properties," Food Hydrocolloids, vol. 43, pp. 252-258, 2015.

[11] M. Wakai and E. Almenar, "Effect of the presence of montmorillonite on the solubility of whey protein isolate films in food model systems with different compositions and $\mathrm{pH}$," Food Hydrocolloids, vol. 43, pp. 612-621, 2015.

[12] R. Sothornvit, S.-I. Hong, D. J. An, and J.-W. Rhim, "Effect of clay content on the physical and antimicrobial properties of whey protein isolate/organo-clay composite films," LWT- Food Science and Technology, vol. 43, no. 2, pp. 279-284, 2010.

[13] R. Sothornvit, J.-W. Rhim, and S.-I. Hong, "Effect of nanoclay type on the physical and antimicrobial properties of whey protein isolate/clay composite films," Journal of Food Engineering, vol. 91, no. 3, pp. 468-473, 2009.

[14] G. Kavoosi, A. Rahmatollahi, S. Mohammad Mahdi Dadfar, and A. Mohammadi Purfard, "Effects of essential oil on the water binding capacity, physico-mechanical properties, antioxidant and antibacterial activity of gelatin films," $L W T$ - Food Science and Technology, vol. 57, no. 2, pp. 556-561, 2014.

[15] A. Mihaly Cozmuta, A. Turila, R. Apjok et al., "Preparation and characterization of improved gelatin films incorporating hemp and sage oils," Food Hydrocolloids, vol. 49, pp. 144-155, 2015.

[16] A. C. Seydim and G. Sarikus, "Antimicrobial activity of whey protein based edible films incorporated with oregano, rosemary and garlic essential oils," Food Research International, vol. 39, no. 5, pp. 639-644, 2006.

[17] S. Shankar, L.-F. Wang, and J.-W. Rhim, "Preparation and properties of carbohydrate-based composite films incorporated with $\mathrm{CuO}$ nanoparticles," Carbohydrate Polymers, vol. 169, pp. 264-271, 2017.

[18] Z. Yu, F. K. Alsammarraie, F. X. Nayigiziki et al., "Effect and mechanism of cellulose nanofibrils on the active functions of biopolymer-based nanocomposite films," Food Research International, vol. 99, pp. 166-172, 2017.

[19] A. Nouri, M. T. Yaraki, M. Ghorbanpour, S. Agarwal, and V. K. Gupta, "Enhanced Antibacterial effect of chitosan film using Montmorillonite/CuO nanocomposite," International Journal of Biological Macromolecules, vol. 109, pp. 1219-1231, 2018.

[20] M. S. Hamid Akash, K. Rehman, and S. Chen, "Natural and synthetic polymers as drug carriers for delivery of therapeutic proteins," Polymer Reviews, vol. 55, no. 3, pp. 371-406, 2015.

[21] M. S. H. Akash, K. Rehman, and S. Chen, "Polymeric-based particulate systems for delivery of therapeutic proteins," Pharmaceutical Development and Technology, vol. 21, no. 3, pp. 367378, 2016.

[22] V. Muriel-Galet, J. P. Cerisuelo, G. López-Carballo, S. Aucejo, R. Gavara, and P. Hernández-Muñoz, "Evaluation of EVOHcoated PP films with oregano essential oil and citral to improve the shelf-life of packaged salad," Food Control, vol. 30, no. 1, pp. 137-143, 2013.

[23] T. Janjarasskul, D. J. Rauch, K. L. McCarthy, and J. M. Krochta, "Barrier and tensile properties of whey protein-candelilla wax film/sheet," LWT- Food Science and Technology, vol. 56, no. 2, pp. 377-382, 2014.

[24] M. Zolfi, F. Khodaiyan, M. Mousavi, and M. Hashemi, "The improvement of characteristics of biodegradable films made from kefiran-whey protein by nanoparticle incorporation," Carbohydrate Polymers, vol. 109, pp. 118-125, 2014.

[25] Z. Pang, H. Deeth, R. Sharma, and N. Bansal, "Effect of addition of gelatin on the rheological and microstructural properties of acid milk protein gels," Food Hydrocolloids, vol. 43, pp. 340-351, 2015.

[26] Ó. L. Ramos, I. Reinas, S. I. Silva et al., "Effect of whey protein purity and glycerol content upon physical properties of edible films manufactured therefrom," Food Hydrocolloids, vol. 30, no. 1, pp. 110-122, 2013.

[27] Y. Shiku, P. Y. Hamaguchi, and M. Tanaka, "Effect of pH on the preparation of edible films based on fish myofibrillar proteins," Fisheries Science, vol. 69, no. 5, pp. 1026-1032, 2003. 
[28] A. Gennadios, C. L. Weller, and C. H. Gooding, "measurementerrors-in-water-vapor-permeability," Journal of Food Engineering, vol. 21, no. 4, pp. 395-409, 1994.

[29] ASTM, "Standard test method for tensile properties of thin plastic sheeting," in Annual book of ASTM Philadelphia: American Society for Testing and Materials, 1995.

[30] AATCC Test method100-2004, "Antibacterial finishes on textile materials: Assessment of. AATCC Committee RA31," 1961.

[31] O. L. Ramos, S. I. Silva, J. C. Soares et al., "Features and performance of edible films, obtained from whey protein isolate formulated with antimicrobial compounds," Food Research International, vol. 45, no. 1, pp. 351-361, 2012.

[32] S. Burt, "Essential oils: their antibacterial properties and potential applications in foods-a review," International Journal of Food Microbiology, vol. 94, no. 3, pp. 223-253, 2004.

[33] S. Benavides, R. Villalobos-Carvajal, and J. E. Reyes, "Physical, mechanical and antibacterial properties of alginate film: effect of the crosslinking degree and oregano essential oil concentration," Journal of Food Engineering, vol. 110, no. 2, pp. 232-239, 2012.

[34] N.-B. Song, J.-H. Lee, M. Al Mijan, and K. B. Song, "Development of a chicken feather protein film containing clove oil and its application in smoked salmon packaging," LWT- Food Science and Technology, vol. 57, no. 2, pp. 453-460, 2014.

[35] R. Schrieber and H. Gareis, Gelatine Handbook: Theory and Industrial Practice, John Wiley \& Sons, 2007.

[36] H. Parastar, M. Jalali-Heravi, H. Sereshti, and A. ManiVarnosfaderani, "Chromatographic fingerprint analysis of secondary metabolites in citrus fruits peels using gas chromatography-mass spectrometry combined with advanced chemometric methods," Journal of Chromatography A, vol. 1251, pp. 176-187, 2012.

[37] O. Obidi, A. Adelowotan, O. Johnson, M. Hassan, and S. Nwachukwu, "Antimicrobial activity of orange oil on selected pathogens," The International Journal of Biotechnology, vol. 2, no. 6, pp. 113-122, 2013.

[38] P. Tongnuanchan, S. Benjakul, and T. Prodpran, "Properties and antioxidant activity of fish skin gelatin film incorporated with citrus essential oils," Food Chemistry, vol. 134, no. 3, pp. 15711579, 2012.

[39] C.-M. Lin, S.-R. Sheu, S.-C. Hsu, and Y.-H. Tsai, "Determination of bactericidal efficacy of essential oil extracted from orange peel on the food contact surfaces," Food Control, vol. 21, no. 12, pp. 1710-1715, 2010. 


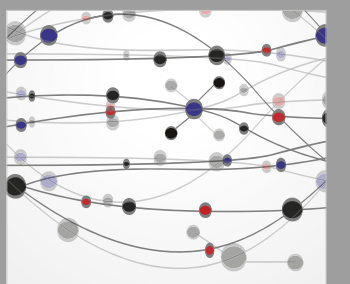

The Scientific World Journal
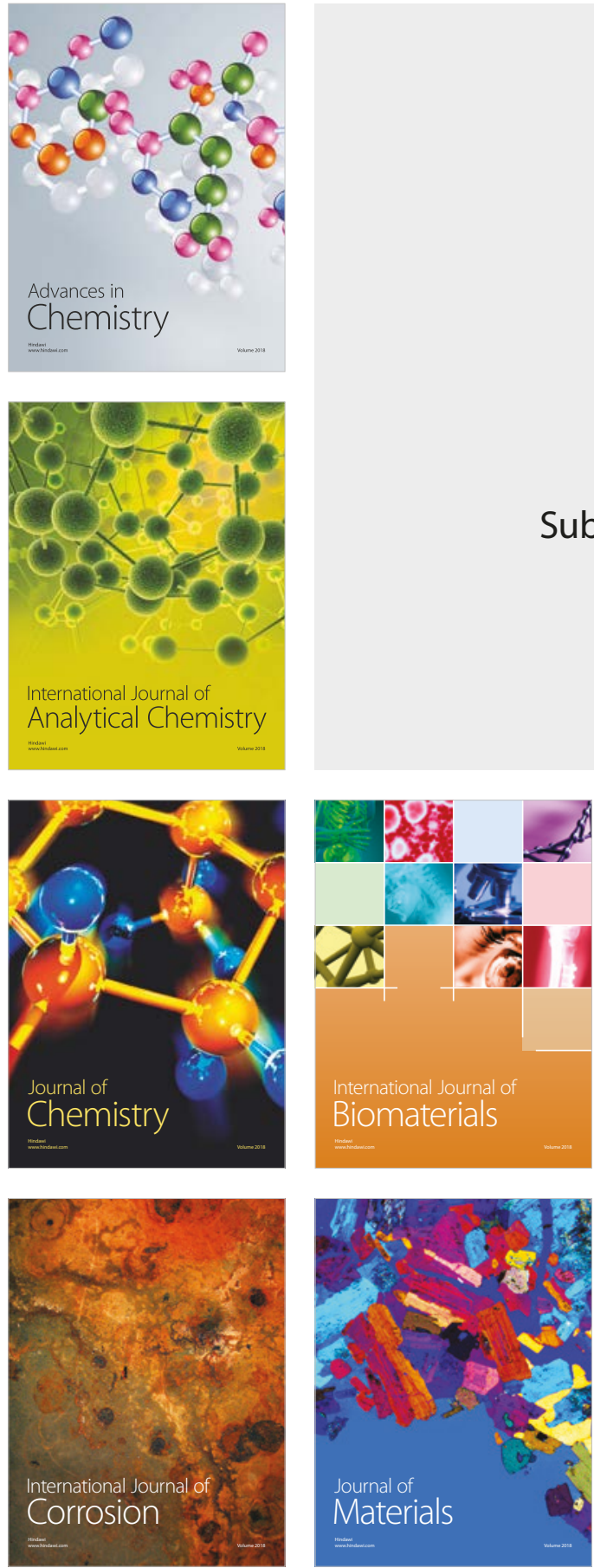

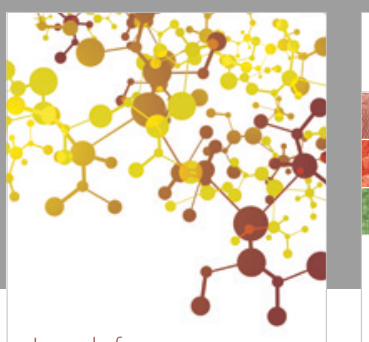

Journal of

Applied Chemistry
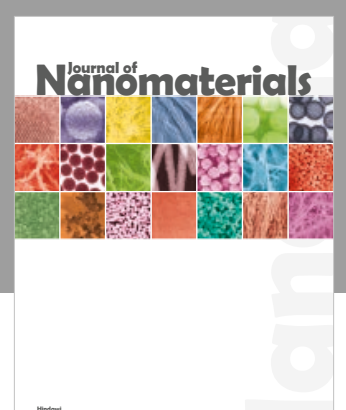

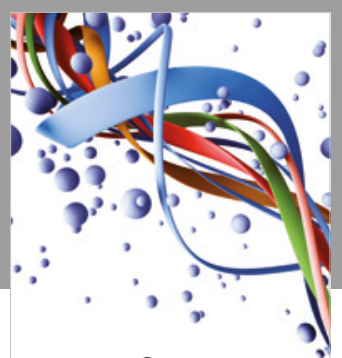

Scientifica

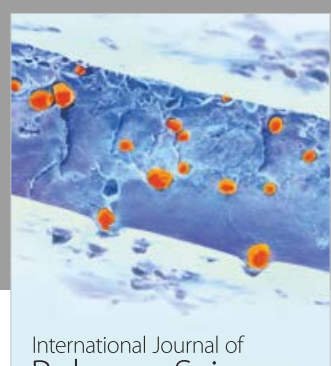

Polymer Science

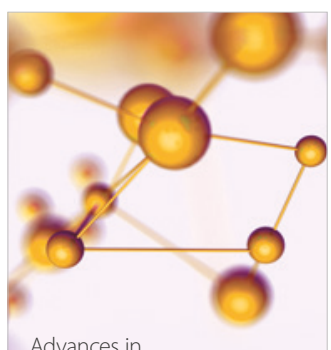

Physical Chemistry
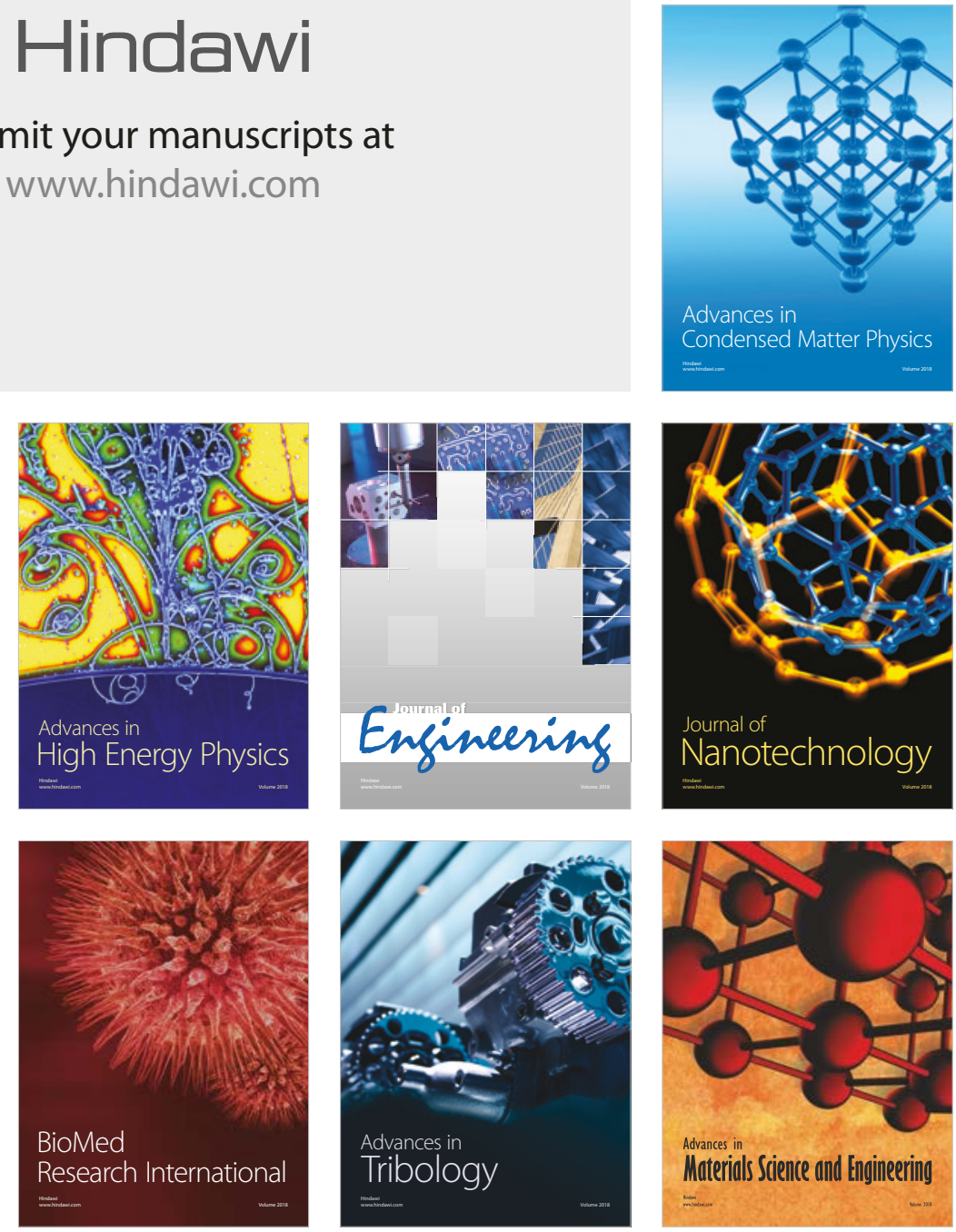